\title{
KOMPETENSI MANAJERIAL KEPALA TENAGA ADMINISTRASI SMA/MA/SMK DI KABUPATEN BELITUNG
}

\begin{abstract}
Based on Government Regulation (PP) of the Republic of Indonesia Number 19 Year 2015 on Education Standard, one of components that should belong to school is education staff. There are several types of education staff, and one of them is administration staff. This research is aimed to describe managerial competency of administration staffs in Belitung Regency and also to overcome the challenge in the implementation of its function. The subject consists of 15 administration heads and 59 administration staffs in various schools. Data collection is conducted by survey and interview. The survey data is analyzed with descriptive statistic using average score, and the interview data is analyzed descriptively. In Belitung Regency, head of administration's managerial competency is excellent in general. However, there are several sub-competencies which need to be improved including organizational staff competency, decision making, resources optimization, staff supervision and conflict management. The competency managerial optimization could not be separated from the role of The Office of Education and Culture.
\end{abstract}

Keywords: competency, managerial, administration, head of administration, education staff standard

Writer:

Tartini

Zulkifli

Correspondence:

tartinikemal@gmail.com

Institution:

Akademi Manajemen Belitung

EKSIS

Vol XI No 2, 2016

ISSN:

$1907-7513$

http://ejournal.stiedewantara.ac.id/

\section{abstrak}

Berdasarkan PP RI Nomor 19 Tahun 2005 Tentang Standar Pendidikan, salah satu komponen sekolah yang harus memenuhi kriteria minimal adalah tenaga kependidikan. Tenaga kependidikan yang dimaksud dalam PP RI tersebut salah satunya adalah tenaga administrasi. Dengan demikian, tenaga administrasi sekolah bisa menunjang proses pendidikan untuk mencapai kualitas yang diharapkan bangsa. Penelitian ini bertujuan untuk mendeskripsikan kompetensi manajerial kepala tenaga administrasi sekolah di Kabupaten Belitung serta mengetahui kendala yang dihadapi dalam melaksanakan fungsi manajerial. Subjek penelitian ini adalah 15 kepala tenaga administrasi sekolah dan 59 staf tenaga administrasi sekolah. Pengumpulan data dilakukan dengan teknik angket dan wawancara. Data angket dianalisis dengan teknik statistik deskriptif menggunakan rerata skor, sedangkan data wawancara dianalisis denga teknik deskriptif. Di Kabupaten Belitung, kompetensi manajerial kepala tenaga admnistrasi sekolah secara keseluruhan termasuk kriteria sangat baik. Meski demikian ada beberapa sub kompetensi yang masih perlu ditingkatkan lagi yaitu kompetensi mengorganisasikan staf, mengambil keputusan, mengoptimalkan pemanfaatan sumber daya, membina staf, dan mengelola konflik. Upaya peningkatan kompetensi manajerial kepala tenaga admnistrasi sekolah tidak terlepas dari peran Dinas Pendidikan dan Kebudayaan. tenaga administrasi, standar tenaga administrasi
Kata Kunci: kompetensi, manajerial, administrasi, kepala 


\section{A. PENDAhULUAN}

Berdasarkan PP RI Nomor 19 Tahun 2005 Tentang Standar Pendidikan, salah satu komponen sekolah yang harus memenuhi kriteria minimal adalah tenaga kependidikan. Tenaga kependidikan yang dimaksud dalam PP RI tersebut salah satunya adalah tenaga administrasi. Standar tenaga administrasi diatur lebih jelas dalam Peraturan Menteri Nomor 24 Tahun 2008 Tentang Standar Tenaga Administrasi Sekolah/Madrasah. Pada pasal 3 dalam PP tersebut dinyatakan bahwa sekolah wajib menerapkan standar tenaga administrasi selambat-lambat 5 tahun setelah peraturan menteri ditetapkan. Hal ini berarti bahwa pada tahun 2013 semua tenaga administrasi sekolah/madrasah wajib memiliki kualifikasi dan kompetensi sesuai dengan peraturan. Dengan demikian, tenaga administrasi sekolah bisa menunjang proses pendidikan untuk mencapai kualitas yang diharapkan bangsa.

Tenaga administrasi memiliki peran penting untuk menunjang proses pendidikan pada satuan pendidikan. Segala aktivitas sekolah membutuhkan kegiatan administrasi misalnya proses pembelajaran membutuhkan presensi siswa, pengarsipan perangkat mengajar, pengurusan surat masuk dan surat keluar, dan sebagainya. Urusan sekolah yang mencakup urusan internal dan eksternal sekolah membutuhkan peran tenaga administrasi. Oleh karena itu, standar kualifikasi dan kompetensi tenaga administrasi wajib dipenuhi oleh sekolahsekolah, tidak terkecuali sekolah yang ada di Kabupaten Belitung.

Ada banyak faktor yang menyebabkan manajemen administrasi di sekolah belum berjalan dengan baik, antara lain kurangnya sarana prasarana, rendahnya kompetensi tenaga administrasi, kualifikasi tenaga administrasi yang tidak sesuai dengan bidang pekerjaannya, kultur sekolah, dan kepemimpinan kepala sekolah. Faktorfaktor tersebut saling berpengaruh terhadap pelaksanaan manajemen administrasi, namun faktor yang sangat berpengaruh terhadap efektivitas manajemen administrasi di sekolah adalah kompetensi tenaga administrasi sekolah. Jika seorang tenaga administrasi sekolah memiliki kompetensi yang seperti diamanatkan dalam Peraturan Menteri Nomor 24 Tahun 2008, maka tenaga administrasi tersebut diharapkan bisa mengatasi segala faktor yang bisa menyebabkan rendahnya efektivitas manajemen administrasi di sekolah.

Salah satu kompetensi yang harus dimiliki oleh seorang tenaga administrasi adalah kompetensi manajerial. Tenaga administrasi diharapkan mampu melaksanakan fungsi-fungsi manajemen sehingga kegiatan administrasi sekolah dapat mendukung proses pendidikan di sekolah. Berdasarkan Peraturan Menteri Nomor 24 Tahun 2008, kompetensi manajerial harus dimiliki oleh kepala tenaga admnistrasi sekolah. Kepala tenaga administrasi harus bisa menjalankan fungsi perencanaan, pelaksanaan, koordinasi, dan pengawasan dalam mengelola administrasi sekolah berdasarkan Standar Nasional Pendidikan. Kompetensi manajerial menjadi kunci utama dalam kegiatan administrasi sekolah yang efektif dan efisien. Kenyataannya, kompetensi majerial tenaga administrasi kurang menjadi perhatian utama sehingga manajemen admnistrasi sekolah kurang mendukung pelaksanaan pendidikan di sekolah.

Berdasarkan informasi dari Dinas Pendidikan dan Kebudayaan Kabupaten Belitung, selama ini belum pernah dilakukan penilaian untuk mengukur kompetensi manajerial kepala tenaga administrasi sekolah. Kepala sekolah hanya melakukan pengawasan dan penilaian terhadap tenaga administrasi 
tanpa menggunakan instrumen penilaian yang baku. Hasil penilaian tersebut menjadi bahan pertimbangan yang kurang tepat untuk menentukan kebijakan terhadap peningkatan kompetensi tenaga administrasi. Akibatnya, pelatihan yang diberikan kepada tenaga administrasi terkadang kurang tepat sasaran dan dana yang dikeluarkan untuk pelatihan tersebut juga menjadi kurang tepat sasaran.

Sekolah di Kabupaten Belitung sangat membutuhkan tenaga administrasi profesional supaya komponen-komponen sekolah yang lainnya bisa bekerja dengan sinergi. Jika komponen-komponen sekolah tidak bekerja dengan sinergi maka akan mengakibatkan rendahnya kualitas sumber daya manusia di Kabupaten Belitung. Oleh karena itu, perlu dilakukan penelitian tentang kompetensi manajerial tenaga administrasi sekolah SMA/MA/SMK di Kabupaten Belitung. Dengan demikian, dapat diperoleh hasil penelitian yang bisa menjadi bahan pertimbangan untuk kebijakan yang dapat meningkatkan kualitas pendidikan di Kabupaten Belitung.

\section{Kompetensi Manajerial Tenaga Administrasi Sekolah}

Secara umum, tenaga administrasi sekolah dapat diartikan sebagai Sumber Daya Manusia yang memiliki kualifikasi dan kompetensi untuk mengerjakan halhal yang meliputi pencatatan, dan tulis menulis untuk menunjang kegiatan sekolah. Surya (2012:3) menerangkan bahwa tenaga administrasi sekolah adalah tenaga kependidikan yang bertugas memberikan dukungan layanan administrasi guna terselenggaranya proses pendidikan di sekolah. Mereka adalah non teaching staff yang bertugas di sekolah yang sering disebut dengan Tata Usaha (TU). Dalam Kepmendiknas No. 053/U/2001 tentang Pedoman Penyusunan Standar Pelayanan Minimal
Penyelenggaraan Persekolahan Bidang Pendidikan Dasar dan Menengah dinyatakan bahwa Tenaga Administrasi Sekolah ialah sumberdaya manusia di sekolah yang tidak terlibat langsung dalam kegiatan belajar mengajar tetapi sangat mendukung keberhasilannya dalam kegiatan administrasi sekolah.

Berdasarkan PP Nomor 19 Tahun 2005 pasal 35, tenaga administrasi sekolah termasuk dalam bagian tenaga kependidikan. Tugas tenaga kependidikan yang dijabarkan dalam UU Nomor 20 Tahun 2003 pasal 39 ayat 1 adalah melaksanakan administrasi, pengelolaan, pengembangan, pengawasan, dan pelayanan teknis. Pada pasal yang sama, tersurat bahwa peran tenaga kependidikan adalah untuk menunjang proses pendidikan pada satuan pendidikan.

Kepala tenaga administrasi dapat disebut sebagai seorang manajer administratif di sekolah. Kepala tenaga administrasi memiliki peran penting dalam mengatur kegiatan administrasi di sekolah sehingga harus memiliki kemampuan manajerial. Berdasarkan hasil penelitian Zahro (2013: 87), kompetensi manajerial menunjukkan pengaruh yang signifikan terhadap variabel kinerja pegawai tata usaha. Hal ini berarti bahwa kinerja pegawai tata usaha dipengaruhi oleh kemampuan kepala tenaga administrasi dalam memanajemen kegiatan administrasi. Berdasarkan Peraturan Menteri Pendidikan Nasional Republik Indonesia Nomor 24 Tahun 2008 Tentang Standar Tenaga Administrasi Sekolah/Madrasah, ada sepuluh (10) kompetensi manajerial kepala tenaga administrasi sekolah yang harus dikuasai yaitu: mendukung pengelolaan Standar Nasional Pendidikan, menyusun program dan laporan kerja, mengorganisasikan staf, mengembangkan staf, mengambil keputusan, menciptakan iklim kerja 
kondusif, mengoptimalkan pemanfaatan sumber daya, membina staf, mengelola konflik, dan menyusun laporan.

\section{B. METODE PENELITIAN}

Penelitian dilaksanakan di sekolah negeri maupun swasta yang ada di Kabupaten Belitung yaitu Sekolah Menengah Atas (SMA), Madrasah Aliyah (MA), dan Sekolah Menengah Kejuruan (SMK). Subjek penelitian ini adalah tenaga administrasi sekolah dan staf tenaga administrasi sekolah di Kabupaten Belitung. Penentuan subjek penelitian dilakukan dengan sampling jenuh karena jumlah tenaga administrasi sekolah pada setiap sekolah yang diteliti jumlah populasinya relatif kecil. Adapun teknik pengumpulan data yang digunakan dalam penelitian ini adalah teknik angket dan wawancara. Angket disusun mengacu pada standar kompetensi manajerial kepala tenaga administrasi sekolah sebagaimana termuat pada Permendiknas Nomor 24 tahun 2008. Teknik wawancara digunakan untuk memperoleh data tentang kendalakendala yang dihadapi oleh kepala tenaga administrasi sekolah dalam menerapkan fungsi manajemen administrasi.

Tabel 1: Konversi Skor dan Kriteria Penilaian

\begin{tabular}{lcl}
\hline \multicolumn{1}{c}{ Rumus } & Rerata Skor & \multicolumn{1}{c}{ Kriteria } \\
\hline $\mathrm{X}>(\mathrm{Mi}+1 \mathrm{Sdi})$ & $\mathrm{X}>3$ & Sangat baik \\
\hline$(\mathrm{Mi})<\mathrm{X} \leq(\mathrm{Mi}+1 \mathrm{Sdi})$ & $2,5<\mathrm{X} \leq 3$ & Baik \\
\hline$(\mathrm{Mi}-1 \mathrm{Sdi})<\mathrm{X} \leq \mathrm{Mi}$ & $2<\mathrm{X} \leq 2,5$ & Cukup Baik \\
\hline $\mathrm{X} \leq(\mathrm{Mi}-1 \mathrm{Sdi})$ & $\mathrm{X} \leq 2$ & Kurang Baik \\
\hline
\end{tabular}

Keterangan:

$$
\begin{aligned}
\mathrm{Mi}= & \text { rata-rata ideal } \\
= & 1 / 2(\text { skor maksimum ideal } \\
& + \text { skor minimum ideal }) \\
= & 1 / 2(4+1)=2,5
\end{aligned}
$$

Sdi $=$ Simpangan baku ideal

$=1 / 6$ (Skor maksimum ideal-skor minimum ideal)

$$
\begin{aligned}
& =1 / 6(4-1)=0,5 \\
\mathrm{X} & =\text { rerata skor } \\
\mathrm{Mi}+1 \mathrm{Sdi} & =2,5+1(0,5) \\
& =3
\end{aligned}
$$

Data angket yang terkumpul akan dianalisis secara deskriptif kuantitatif. Analisis data dilakukan melalui perhitungan rata-rata skor kemudian dilakukan perhitungan grand mean setiap sub komponen dan indikator evaluasi dengan bantuan program komputer Microsoft Office Excel 2007. Grand mean yang diperoleh akan dibandingkan dengan kriteria penilaian yang telah ditentukan.

Kriteria kompetensi kepala tenaga administrasi sekolah SMA/MA/SMK di Kabupaten Belitung dikatagorikan berdasar model distribusi normal. Azwar (2010: 106) menjelaskan asumsi bahwa skor subjek dalam kelompoknya merupakan estimasi terhadap skor subjek dalam populasi dan bahwa skor subjek dalam populasinya terdistribusi secara normal. Instrumen angket menggunakan empat skala, sehingga skor tertinggi adalah 4 (empat), sedangkan skor terendah adalah 1 (satu). Konversi skor dan kriteria dari data kuesioner pada distribusi normal dengan menggunakan empat kriteria dapat dilihat pada tabel berikut.

$$
\mathrm{Mi}-1 \mathrm{Sdi}=2,5-1(0,5)
$$

$$
=2
$$

Data wawancara akan dianalisis secara deskriptif. Berdasarkan analisis data akan ditarik kesimpulan dan mengajukan saran/rekomendasi kepada pihak-pihak yang berkepentingan dengan tenaga administrasi sekolah.

\section{HASIL DAN PEMBAHASAN}

Berdasarkan hasil penelitian terhadap 14 kepala tenaga administrasi sekolah di Kabupaten Belitung, secara 
keseluruhan data penelitian menunjukkan bahwa kompetensi manajerial kepala tenaga administrasi sekolah SMA/MA/SMK di Kabupaten Belitung termasuk kriteria sangat baik dengan perolehan rerata 3,44. Meski demikian, ada indikator kompetensi manajerial yang masih lemah jika dilihat dari nilai rerata setiap indikator pada setiap sekolah. Artinya, meskipun kompetensi manajerial kepala tenaga admnistrasi sekolah secara keseluruhan bisa dikatakan sangat baik, namun masih ada sub kompetensi manajerial yang perlu ditingkatkan. Berikut ini gambaran setiap kompetensi manajerial kepala tenaga admnistrasi sekolah SMA/MA/SMK di Kabupaten Belitung.

\section{Mendukung Pengelolaan Standar Nasional Pendidikan}

Ada tiga hal yang harus dilakukan oleh kepala tenaga admnistrasi sekolah untuk mendukung pengelolaan standar nasional pendidikan, yaitu: membantu merencanakan pendidikan berdasarkan standar nasional pendidikan, membantu mengkoordinasikan pelaksanaan standar nasional pendidikan, dan membantu mendokumentasikan hasil pemantauan pelaksanaan standar nasional pendidikan. Berdasarkan hasil angket dari 14 sekolah yang diteliti, ada 12 kepala tenaga admnistrasi sekolah yang sudah mendukung pengelolaan standar nasional pendidikan dengan sangat baik, dua lainnya termasuk kriteria baik. Berikut ini perolehan hasil angket untuk kompetensi manajerial kepala tenaga admnistrasi sekolah dalam hal mendukung pengelolaan standar nasional pendidikan.

Tabel 2: Kompetensi Manajerial:

Mendukung Pengelolaan Standar Nasional Pendidikan

\begin{tabular}{lrl}
\hline \multicolumn{1}{c}{ NAMA SEKOLAH } & $\mathrm{R}$ & \multicolumn{1}{c}{ KRITERIA } \\
\hline SMA 1 TANJUNGPANDAN & 3,04 & Sangat Baik \\
\hline SMAN 2 TANJUNGPANDAN & 4,00 & Sangat Baik \\
\hline SMAN 1 MEMBALONG & 3,33 & Sangat Baik \\
\hline SMA PGRI & 4,00 & Sangat Baik \\
\hline SMA MUHAMMADIYAH & 3,89 & Sangat Baik \\
\hline SMK YAPERBEL TP & 4,00 & Sangat Baik \\
\hline SMKN 1 TANJUNGPANDAN & 3,33 & Sangat Baik \\
\hline SMKN 2 TANJUNGPANDAN & 4,00 & Sangat Baik \\
\hline SMKN 3 TANJUNGPANDAN & 2,56 & Baik \\
\hline SMKN 1 BADAU & 3,33 & Sangat Baik \\
\hline MAN TANJUNGPANDAN & 3,86 & Sangat Baik \\
\hline SMK SWAKARYA TANJUNGPANDAN & 3,08 & Sangat Baik \\
\hline SMAN 1 SIJUK & 2,67 & Baik \\
\hline SMKN SELAT NASIK & 3,83 & Sangat Baik
\end{tabular}

Sumber: Data Primer diolah, 2016

Dari hasil wawancara kepada kepala tenaga admnistrasi sekolah, diperoleh informasi bahwa hal yang mereka lakukan dalam mendukung pengelolaan standar nasional pendidikan adalah dengan cara ikut terlibat mempersiapkan hal-hal yang diperlukan untuk pengelolaan standar nasional pendidikan seperti membuat dokumendokumen pendukung standar nasional pendidikan, mendokumentasikan hasil kegiatan akreditasi, dan ikut serta dalam rapat yang diadakan oleh sekolah untuk membahas persiapan akreditasi. Keterlibatan kepala tenaga admistrasi dalam pengelolaan standar nasional pendidikan terbatas pada tugas pokok dalam kegiatan admnistrasi, belum berperan maksimal dalam perencanaan pendidikan berdasarkan standar nasional. 
Kepala tenaga admnistrasi beserta stafnya hanya sebagai pelaksana dari rencanarencana yang telah dibuat oleh sekolah. Jadi, keterlibatan kepala tenaga admnistrasi sekolah dalam pengelolan standar nasional pendidikan lebih dominan pada kegiatan mengkoordinasikan pelaksanaan standar nasional pendidikan, dan membantu mendokumentasikan hasil pemantauan pelaksanaan standar nasional pendidikan.

\section{Menyusun Program dan Laporan Kerja}

Ada enam hal yang bisa dilakukan oleh kepala tenaga admnistrasi sekolah dalam menyusun program dan laporan kerja yaitu menentukan prioritas, melakukan penugasan, merumuskan tujuan, menetapkan sumber daya, menentukan strategi penyelesaian pekerjaan, dan menyusun laporan. Berikut ini hasil angket tentang menyusun program dan laporan kerja.

Tabel 3: Kompetensi Manajerial:

Menyusun Program dan Laporan Kerja

\begin{tabular}{lll}
\hline \multicolumn{1}{c}{ NAMA SEKOLAH } & R & \multicolumn{1}{c}{ KRITERIA } \\
\hline SMA 1 TANJUNGPANDAN & 3,33 & Sangat Baik \\
\hline SMAN 2 TANJUNGPANDAN & 3,97 & Sangat Baik \\
\hline SMAN 1 MEMBALONG & 3,51 & Sangat Baik \\
\hline SMA PGRI & 4,00 & Sangat Baik \\
\hline SMA MUHAMMADIYAH & 3,82 & Sangat Baik \\
\hline SMK YAPERBEL TP & 3,41 & Sangat Baik \\
\hline SMKN 1 TANJUNGPANDAN & 3,51 & Sangat Baik \\
\hline SMKN 2 TANJUNGPANDAN & 3,59 & Sangat Baik \\
\hline SMKN 3 TANJUNGPANDAN & 3,36 & Sangat Baik \\
\hline SMKN 1 BADAU & 3,36 & Sangat Baik \\
\hline MAN TANJUNGPANDAN & 4,00 & Sangat Baik \\
\hline SMK SWAKARYA TANJUNGPANDAN & 3,15 & Sangat Baik \\
\hline SMAN 1 SIJUK & 2,51 & Baik \\
\hline SMKN SELAT NASIK & 3,56 & Sangat Baik
\end{tabular}

Sumber: Data Primer diolah, 2016

Berdasarkan hasil angket, ada 12 kepala tenaga admnistrasi sekolah yang telah memiliki kompetensi dalam menyusun program dan laporan kerja dengan sangat baik, sedangkan dua kepala tenaga admnistrasi lainnya termasuk kriteria baik. Artinya, kepala tenaga admnistrasi sekolah telah memiliki kompetensi dalam menyusun program dan laporan kerja. Namun, berdasarkan hasil wawancara, semua kepala tenaga admnistrasi sekolah belum menyusun program kerja untuk tahun ajaran yang sedang berjalan dikarenakan kesibukan mereka dalam pengurusan tahun ajaran baru. Kondisi ini menunjukkan bahwa kepala tenaga administrasi sekolah sudah mampu menyusun program kerja dengan baik namun belum mampu mengadakan program kerja dengan tepat waktu.

Kepala tenaga admnistrasi sekolah membuat program kerja berdasarkan panduan dari dinas sehingga kompetensi kepala tenaga administrasi sekolah dalam menyusun program kerja bisa dikatakan sangat baik. Laporan disusun dan dilaporkan kepada dinas setiap setahun sekali. Dalam penyusunan laporan, kepala tenaga admnistrasi melibatkan pegawai tenaga admnistrasi sesuai dengan bidangnya. Laporan yang dibuat oleh masing-masng bidang akan direkap oleh kepala tenaga admnistrasi dan disusun mejadi laporan yang sempurna.

Berbeda halnya dengan SMA Muhammadiyah, laporan kerja hanya dilaporkan kepada kepala sekolah. 
Sekolah yang dibawah naungan Departeman Agama yaitu MAN Tanjungpandan dan MA Darul Arofah, kepala teanga administrasi menyusun laporan kerja dan melaporkannya secara tertulis kepada Kementerian Agama Kabupaten Belitung.

\section{Mengorganisasikan Staf}

Kompetensi dalam hal mengorganisasikan staf akan membuat kerja staf menjadi terarah dan mampu mencapai tujuan yang ditentukan. Ada delapan hal yang perlu dilakukan oleh kepala tenaga admnistrasi sekolah untuk mengorganisasikan staf, yaitu menyusun uraian tugas tenaga kependidikan, memberikan pemahaman tupoksi, menyesuaikan rencana kerja dengan kemampuan organisasi, menggunakan pendekatan persuatif untuk mengorganisasikan staf, berinisiatif dalam pertemuan, meningkatkan keefektifan kerja, mengakomodasi ideide staf, dan menjabarkan kebijakan organisasi. Berdasarkan hasil angket yang disebar kepada tenaga administrasi sekolah, 13 kepala tenaga admnistrasi sekolah termasuk kriteria sangat baik dalam mengorganisasikan staf, sedangkan satu sekolah lainnnya termasuk kriteria cukup baik. Artinya, ada satu kepala tenaga admnistrasi yang belum memiliki kompetensi mengorganisasikan staf dengan sangat baik atau belum sesuai harapan. Kepala tenaga admnistrasi sekolah tersebut hanya memberikan tanggungjawab sesuai tupoksi kepada stafnya.

Tabel 4: Kompetensi Manajerial:

Mengorganisasikan Staf

\begin{tabular}{lcll}
\hline \multicolumn{1}{c}{ NAMA SEKOLAH } & R & \multicolumn{1}{c}{ KRITERIA } \\
\hline SMA 1 TANJUNGPANDAN & 3,16 & Sangat Baik \\
\hline SMAN 2 TANJUNGPANDAN & 3,67 & Sangat Baik \\
\hline SMAN 1 MEMBALONG & 3,63 & Sangat Baik \\
\hline SMA PGRI & 4,00 & Sangat Baik \\
\hline SMA MUHAMMADIYAH & 3,58 & Sangat Baik \\
\hline SMK YAPERBEL TANJUNGPANDAN & 3,13 & Sangat Baik \\
\hline SMKN 1 TANJUNGPANDAN & 3,39 & Sangat Baik \\
\hline SMKN 2 TANJUNGPANDAN & 3,58 & Sangat Baik \\
\hline SMKN 3 TANJUNGPANDAN & 3,42 & Sangat Baik \\
\hline SMKN 1 BADAU & 3,23 & Sangat Baik \\
\hline MAN TANJUNGPANDAN & 3,98 & Sangat Baik \\
\hline SMK SWAKARYA TANJUNGPANDAN & 3,06 & Sangat Baik \\
\hline SMAN 1 SIJUK & 2,44 & Cukup Baik \\
\hline SMKN SELAT NASIK & 3,56 & Sangat Baik
\end{tabular}

Berdasarkan hasil wawancara kepada 15 kepala tenaga administrasi sekolah diperoleh informasi bahwa kepala tenaga administrasi telah menyusun uraian tugas tenaga kependidikan. Tugas pokok dan fungsi tenaga admnistrasi disampaikan secara tertulis. Pertemuan formal antara kepala tenaga admnistrasi sekolah dengan stafnya sangat jarang terjadi. Hanya kepala tenaga admnistrasi sekolah SMA Negeri 2 Tanjungpandan yang menyatakan pernah melakukan pertemuan dengan stafnya untuk membahas hal-hal yang perlu disiapkan dan dilakukan dalam kegiatan admnistrasi sekolah. Kepala tenaga admnistrasi lainnya tidak pernah melakukan pertemuan khusus karena diskusi bisa dilakukan di ruangan kerja dengan berkomunikasi secara santai. Diskusi tersebut dirasa oleh kepala tenaga administrasi sekolah lebih efektif untuk mendapatkan ide-ide dari stafnya. 


\section{Mengembangkan Staf}

Ada tiga hal yang harus dilakukan oleh kepala tenaga administrasi sekolah untuk mengembangkan staf yaitu memberikan arahan kerja, memotivasi staf, dan memberdayakan staf. Diantara 14 kepala tenaga admnistrasi, ada satu kepala tenaga admnistrasi yang memiliki kompetensi kurang baik (perolehan rerata skor 2,00) dalam hal mengembangkan staf. Artinya, kepala tenaga administrasi sekolah tersebut belum mampu memberikan arah kerja kepada stafnya, memotivasi staf, dan memberdayakan stafnya.

Tabel 5: Kompetensi Manajerial: Mengembangkan Staf

\begin{tabular}{lll}
\hline \multicolumn{1}{c}{ NAMA SEKOLAH } & $\mathrm{R}$ & \multicolumn{1}{c}{ KRITERIA } \\
\hline SMA 1 TANJUNGPANDAN & 3.29 & Sangat Baik \\
\hline SMAN 2 TANJUNGPANDAN & 4.00 & Sangat Baik \\
\hline SMAN 1 MEMBALONG & 4.00 & Sangat Baik \\
\hline SMA PGRI & 4.00 & Sangat Baik \\
\hline SMA MUHAMMADIYAH & 3.78 & Sangat Baik \\
\hline SMK YAPERBEL TANJUNGPANDAN & 3.33 & Sangat Baik \\
\hline SMKN 1 TANJUNGPANDAN & 3.50 & Sangat Baik \\
\hline SMKN 2 TANJUNGPANDAN & 3.60 & Sangat Baik \\
\hline SMKN 3 TANJUNGPANDAN & 3.22 & Sangat Baik \\
\hline SMKN 1 BADAU & 3.39 & Sangat Baik \\
\hline MAN TANJUNGPANDAN & 3.95 & Sangat Baik \\
\hline SMK SWAKARYA TANJUNGPANDAN & 3.33 & Sangat Baik \\
\hline SMAN 1 SIJUK & 2.00 & Kurang Baik \\
\hline SMKN SELAT NASIK & 3.00 & Baik
\end{tabular}

Berdasarkan hasil wawancara, kepala tenaga administrasi sekolah yang kompetensi manajerialnya termasuk kriteria kurang baik dalam mengembangkan staf diperoleh informasi bahwa kepala tenaga administrasi tersebut mengutamakan pengalaman dalam pengembangan staf. Artinya, kepala tenaga administrasi tersebut mengembangkan stafnya belum memperhatikan hal-hal yang dibutuhkan oleh stafnya sehingga pengembangan staf kurang optimal.

\section{Mengambil Keputusan}

Diantara 14 kepala tenaga administrasi sekolah, ada satu kepala tenaga administrasi sekolah yang baru mencapai kriteria cukup baik dalam mengambil keputusan, sedangkan 13 kepala tenaga admnistrasi lainnya sudah memiliki kompetensi yang sangat baik. Hal-hal yang perlu dilakukan oleh kepala tenaga admnistrasi sekolah dalam mengambil keputusan adalah: mengidentifikasi masalah, merumuskan masalah, menentukan tindakan yang tepat, memperhitungkan resiko, dan mengambil keputusan partisipatif.

Tabel 6: Kompetensi Manajerial:

Mengambil Keputusan

\begin{tabular}{llll}
\hline \multicolumn{1}{c}{ NAMA SEKOLAH } & \multicolumn{1}{c}{ K } & \multicolumn{1}{c}{ KRITERIA } \\
\hline SMA 1 TANJUNGPANDAN & 3,08 & Sangat Baik \\
\hline SMAN 2 TANJUNGPANDAN & 3,67 & Sangat Baik \\
\hline SMAN 1 MEMBALONG & 3,55 & Sangat Baik \\
\hline SMA PGRI & 4,00 & Sangat Baik \\
\hline SMA MUHAMMADIYAH & 3,60 & Sangat Baik \\
\hline SMK YAPERBEL TANJUNGPANDAN & 3,95 & Sangat Baik \\
\hline SMKN 1 TANJUNGPANDAN & 3,55 & Sangat Baik \\
\hline SMKN 2 TANJUNGPANDAN & 3,88 & Sangat Baik \\
\hline SMKN 3 TANJUNGPANDAN & 3,13 & Sangat Baik
\end{tabular}




\begin{tabular}{lrl} 
SMKN 1 BADAU & 3,53 & Sangat Baik \\
\hline MAN TANJUNGPANDAN & 4,00 & Sangat Baik \\
\hline SMK SWAKARYA TANJUNGPANDAN & 3,65 & Sangat Baik \\
\hline SMAN 1 SIJUK & 2,50 & Cukup Baik \\
\hline SMKN SELAT NASIK & 3,40 & Sangat Baik \\
\hline
\end{tabular}

Sumber: Data Primer diolah, 2016

Berdasarkan hasil wawancara, ada sembilan kepala tenaga administrasi sekolah menyatakan bahwa mereka selalu melibatkan staf dalam mengambil keputusan. Hal ini berarti bahwa kepala tenaga administrasi telah mengambil keputusan secara partisipatif. Ada satu kepala tenaga admnistrasi yang belum berani mengambil keputusan, sehingga kepala tenaga admnistrasi tersebut menyerahkan keputusan kepada kepala sekolah. Sedangkan kepala tenaga admnistrasi lainnya melakukan pengambilan keputusan sendiri, jika tidak

bisa maka mereka meminta bantuan kepala sekolah.

\section{Menciptakan Iklim Kerja Kondusif}

Iklim kerja yang kondusif sangat diperlukan oleh staf supaya mereka bisa bekerja dengan maksimal. Oleh karena itu, kepala tenaga administrasi sekolah harus memiliki kompetensi dalam menciptakan iklim kerja kondusif. Ada tiga hal yang bisa dilakukan oleh kepala tenaga admnistrasi sekolah dalam menciptakan iklim kerja kondusif yaitu menciptakan hubungan kerja harmonis, melakukan komunikasi interaktif, dan menghargai pendapat rekan kerja.

Tabel 7: Kompetensi Manajerial:

Menciptakan Iklim Kerja Kondusif

\begin{tabular}{llll} 
& \multicolumn{1}{c}{ NAMA SEKOLAH } & \multicolumn{1}{c}{ KRITERIA } \\
\hline SMA 1 TANJUNGPANDAN & 3,50 & Sangat Baik \\
\hline SMAN 2 TANJUNGPANDAN & 4,00 & Sangat Baik \\
\hline SMAN 1 MEMBALONG & 4,00 & Sangat Baik \\
\hline SMA PGRI & 4,00 & Sangat Baik \\
\hline SMA MUHAMMADIYAH & 4,00 & Sangat Baik \\
\hline SMK YAPERBEL TANJUNGPANDAN & 4,00 & Sangat Baik \\
\hline SMKN 1 TANJUNGPANDAN & 3,75 & Sangat Baik \\
\hline SMKN 2 TANJUNGPANDAN & 3,40 & Sangat Baik \\
\hline SMKN 3 TANJUNGPANDAN & 3,67 & Sangat Baik \\
\hline SMKN 1 BADAU & 3,67 & Sangat Baik \\
\hline MAN TANJUNGPANDAN & 3,86 & Sangat Baik \\
\hline SMK SWAKARYA TANJUNGPANDAN & 3,92 & Sangat Baik \\
\hline SMAN 1 SIJUK & 3,00 & Baik \\
\hline SMKN SELAT NASIK & 3,83 & Sangat Baik \\
\hline Sumb : Data Prim din
\end{tabular}

Sumber: Data Primer diolah, 2016

Berdasarkan data angket diperoleh informasi bahwa 13 kepala tenaga admnistrasi sekolah memiliki kompetensi menciptakan iklim kerja kondusif dengan sangat baik, sedangkan satu kepala tenaga admnistrasi sekolah termasuk kriteria baik. Hal ini berarti bahwa kepala tenaga administrasi sekolah telah mampu menciptakan iklim kerja yang kondusif bagi pegawai.
Hasil wawancara menunjukkan bahwa seluruh kepala tenaga admnistrasi menciptakan iklim kerja kondusif dengan kekeluargaan, komunikatif dan kerjasama. Namun ada satu kepala tenaga admnistrasi yang merasa kesulitan dalam menciptakan iklim kerja kondusif karena ada beberapa staf yang sulit diajak kerjasa sama. Hal ini menunjukkan bahwa kompetensi manajerial untuk menciptakan iklim kerja kondusif yang 
dimiliki oleh kepala tenaga administrasi tersebut masih perlu ditingkatkan.

\section{Mengoptimalkan \\ Pemanfaatan Sumber Daya}

Ada dua hal yang perlu dilakukan oleh kepala tenaga admnistrasi sekolah untuk mengoptimalkan pemanfaatan sumber daya yaitu memberdayakan aset organisasi, dan mengadministrasikan aset organisasi. Berdasarkan hasil angket, ada satu kepala tenaga admnistrasi sekolah yang belum memiliki kompetensi yang maksimal dengan kriteria cukup baik, satu kepala tenaga administrasi memiliki kriteria baik, dan 12 kepala tenaga admnistrasi lainnya termasuk kriteria sangat baik. Data tersebut menunjukkan bahwa masih ada kepala tenaga admnistrasi sekolah di Belitung yang belum mengotimalkan pemanfaatan sumber daya dengan sangat baik.

Tabel 8: Kompetensi Manajerial:

Mengoptimalkan Pemanfaatan Sumber Daya

\begin{tabular}{lll}
\hline \multicolumn{1}{c}{ NAMA SEKOLAH } & $\mathrm{R}$ & \multicolumn{1}{c}{ KRITERIA } \\
\hline SMA 1 TANJUNGPANDAN & 3,13 & Sangat Baik \\
\hline SMAN 2 TANJUNGPANDAN & 3,67 & Sangat Baik \\
\hline SMAN 1 MEMBALONG & 4,00 & Sangat Baik \\
\hline SMA PGRI & 4,00 & Sangat Baik \\
\hline SMA MUHAMMADIYAH & 3,50 & Sangat Baik \\
\hline SMK YAPERBEL TANJUNGPANDAN & 2,50 & Cukup Baik \\
\hline SMKN 1 TANJUNGPANDAN & 3,25 & Sangat Baik \\
\hline SMKN 2 TANJUNGPANDAN & 3,70 & Sangat Baik \\
\hline SMKN 3 TANJUNGPANDAN & 3,33 & Sangat Baik \\
\hline SMKN 1 BADAU & 3,08 & Sangat Baik \\
\hline MAN TANJUNGPANDAN & 4,00 & Sangat Baik \\
\hline SMK SWAKARYA TANJUNGPANDAN & 3,38 & Sangat Baik \\
\hline SMAN 1 SIJUK & 3,00 & Baik \\
\hline SMKN SELAT NASIK & 4,00 & Sangat Baik \\
\hline
\end{tabular}

Sumber: Data Primer diolah, 2016

Berdasarkan hasil wawancara dengan kepala tenaga admnistrasi sekolah, mereka telah melakukan pengadmininistrasian aset organisasi berupa sumber daya manusia, sarana dan prasarana, dan dana. Semua aset organisasi tersebut telah diberdayakan sesuai dengan fungsinya.

\section{Membina Staf}

Kepala tenaga admnistrasi sekolah harus mampu membina staf supaya kinerja staf semakin meningkat. Ada empat hal yang bisa dilakukan oleh kepala tenaga admnistrasi sekolah untuk membina staf yaitu: memantau pekerjaan staf, menilai proses dan hasil kerja, memberikan umpan balik, dan melaporkan hasil pembinaan.

Tabel 9: Kompetensi Manajerial:

Membina Staf

\begin{tabular}{lcll}
\hline \multicolumn{1}{c}{ NAMA SEKOLAH } & $\mathrm{R}$ & \multicolumn{1}{c}{ KRITERIA } \\
\hline SMA 1 TANJUNGPANDAN & 3,00 & Baik \\
\hline SMAN 2 TANJUNGPANDAN & 3,67 & Sangat Baik \\
\hline SMAN 1 MEMBALONG & 4,00 & Sangat Baik \\
\hline SMA PGRI & 4,00 & Sangat Baik \\
\hline SMA MUHAMMADIYAH & 3,56 & Sangat Baik \\
\hline SMK YAPERBEL TANJUNGPANDAN & 3,17 & Sangat Baik \\
\hline SMKN 1 TANJUNGPANDAN & 3,42 & Sangat Baik \\
\hline SMKN 2 TANJUNGPANDAN & 3,33 & Sangat Baik \\
\hline SMKN 3 TANJUNGPANDAN & 3,00 & Baik \\
\hline SMKN 1 BADAU & 3,22 & Sangat Baik
\end{tabular}




\begin{tabular}{lll} 
MAN TANJUNGPANDAN & 3,95 & Sangat Baik \\
\hline SMK SWAKARYA TANJUNGPANDAN & 2,92 & Baik \\
\hline SMAN 1 SIJUK & 2,33 & Cukup Baik \\
\hline SMKN SELAT NASIK & 3,17 & Sangat Baik \\
\hline Sumber: Data Primer diolah, 2016 & &
\end{tabular}

Berdasarkan data angket diperoleh informasi bahwa ada satu kepala tenaga admnistrasi sekolah yang kompetensinya baru termasuk kriteria cukup baik, tiga kepala tenaga admnistrasi sekolah memiliki kriteria baik, dan sepuluh kepala tenaga administrasi sekolah sudah memiliki kriteria sangat baik. Hal ini menunjukan bahwa masih perlu peningkatan kompetensi membina staf.

Hasil wawancara dengan 15 kepala tenaga administrasi menunjukkan bahwa pembinaan staf dilakukan dengan memberikan peringatan dan pengertian akan tanggungjawab staf secara kekeluargaan. Penilaian proses dan hasil kerja dengan menggunakan instrument yang standar belum pernah dilakukan karena kepala tenaga admnistrasi belum mengetahui cara melakukan penilaian secara formal. Penilaian hanya dilakukan secara tidak formal, apabila staf bekerja dengan baik maka akan dipuji, jika staf bekerja dengan kurang baik amaka akan diberikan pengarahan. Hasil binaan tidak pernah disampaikan kepada kepala sekolah. Diantara 15 kepala tenaga admnistrasi, ada satu kepala tenaga admnistrasi yang belum melakukan pembinan kepada staf karena ada pegawai yang tidak mau diatur.

\section{Mengelola Konflik}

Konflik yang terjadi dalam lingkungan kerja akan menghambat kinerja staf. Oleh karena itu, kepala tenaga admnistrasi sekolah harus memiliki kompetensi mengelola konflik yaitu mengidentifikasi sumber konflik, mengidentifikasi alternatif penyelesaian, menggali pendapat-pendapat, dan memilih alternatif terbaik. Data angket menunjukkan ada dua kepala tenaga administrasi sekolah yang memiliki kriteria kurang baik dalam mengelola konflik. Satu kepala tenaga admnistasi sekolah termasuk kriteria cukup baik, satu kepala tenaga administrasi termasuk criteria baik, dan sepuluh kepala tenaga admnistrasi lainnya termasuk kriteria sangat baik. Hal ini berarti bahwa masih perlu pembinaan kepala kepala tengaa administrasi sekolah untuk meningkatkan kompetensi mengelola konflik.

Tabel 10: Kompetensi Manajerial:

Mengelola Konflik

\begin{tabular}{llll}
\hline \multicolumn{1}{c}{ NAMA SEKOLAH } & $\mathrm{R}$ & \multicolumn{1}{c}{ KRITERIA } \\
\hline SMA 1 TANJUNGPANDAN & 3,19 & Sangat Baik \\
\hline SMAN 2 TANJUNGPANDAN & 3,67 & Sangat Baik \\
\hline SMAN 1 MEMBALONG & 1,00 & Kurang Baik \\
\hline SMA PGRI & 4,00 & Sangat Baik \\
\hline SMA MUHAMMADIYAH & 3,75 & Sangat Baik \\
\hline SMK YAPERBEL TANJUNGPANDAN & 2,38 & Cukup Baik \\
\hline SMKN 1 TANJUNGPANDAN & 3,31 & Sangat Baik \\
\hline SMKN 2 TANJUNGPANDAN & 3,55 & Sangat Baik \\
\hline SMKN 3 TANJUNGPANDAN & 3,00 & Baik \\
\hline SMKN 1 BADAU & 3,04 & Sangat Baik \\
\hline MAN TANJUNGPANDAN & 4,00 & Sangat Baik \\
\hline SMK SWAKARYA TANJUNGPANDAN & 3,25 & Sangat Baik \\
\hline SMAN 1 SIJUK & 2,00 & Kurang Baik \\
\hline SMKN SELAT NASIK & 3,13 & Sangat Baik
\end{tabular}


Berdasarkan hasil wawancara, ada satu kepala tenaga admnistrasi yang tidak mampu mengelola konflik yang terjadi antara staf dengan kepala tenaga admnistrasi sehingga konflik tersebut dibiarkan tanpa ada langkah penyelesaian. Kepala tenaga administrasi tersebut perlu mengidentifikasi sumber konflik, mengidentifikasi alternative penyelesaian, menggali pendapatpendapat, dan memilik alternatih terbaik. Jika langkah-langkah tersebut juga belum mampu menyelesaikan konflik maka perlu bantuan pihak ketiga misalnya kepala sekolah. Dengan demikian, konflik akan dapat diselesaikan dan tidak menghambat kegiatan administrasi. Kepala tenaga admnistrasi lainnya menyatakan bahwa tidak pernah ada konflik yang menghambat kerja staf, jika ada maka akan segera diselesaikan secara kekeluargaan dan melibatkan kepala sekolah jika diperlukan.

\section{Menyusun Laporan}

Berdasarkan hasil angket, 12 kepala tenaga admnistrasi sekolah memiliki kriteria sangat baik dalam menyusun laporan, sedangkan dua kepala tenaga administrasi lainnya termasuk kriteria baik. Hal ini berarti bahwa sebagian besar kepala tenaga administrasi sekolah telah menyusun laporan dengan cara mengkoordinasikan penyusunan laporan dan mengendalikan penyusunan laporan.

Tabel 11: Kompetensi Manajerial:

Menyusun Laporan

\begin{tabular}{lcl}
\hline \multicolumn{1}{c}{ NAMA SEKOLAH } & $\mathrm{R}$ & \multicolumn{1}{c}{ KRITERIA } \\
\hline SMA 1 TANJUNGPANDAN & 3,38 & Sangat Baik \\
\hline SMAN 2 TANJUNGPANDAN & 3,67 & Sangat Baik \\
\hline SMAN 1 MEMBALONG & 4,00 & Sangat Baik \\
\hline SMA PGRI & 4,00 & Sangat Baik \\
\hline SMA MUHAMMADIYAH & 4,00 & Sangat Baik \\
\hline SMK YAPERBEL TANJUNGPANDAN & 4,00 & Sangat Baik \\
\hline SMKN 1 TANJUNGPANDAN & 3,25 & Sangat Baik \\
\hline SMKN 2 TANJUNGPANDAN & 3,20 & Sangat Baik \\
\hline SMKN 3 TANJUNGPANDAN & 3,50 & Sangat Baik \\
\hline SMKN 1 BADAU & 3,83 & Sangat Baik \\
\hline MAN TANJUNGPANDAN & 4,00 & Sangat Baik \\
\hline SMK SWAKARYA TANJUNGPANDAN & 3,00 & Baik \\
\hline SMAN 1 SIJUK & 3,00 & Baik \\
\hline SMKN SELAT NASIK & 3,50 & Sangat Baik
\end{tabular}

Berdasarkan hasil wawancara, kepala tenaga administrasi sekolah selalu membuat laporan sebagai bentuk pertanggungjawaban mereka terhadap pekerjaan. Kepala tenaga admnistrasi mengkoordinasikan penyusunan laporan dengan cara meminta setiap pelaksana urusan membuat laporan, kemudian setiap laporan dari pelaksana urusan tersebut akan disusun oleh kepala tenaga administrasi sekolah menjadi laporan yang lengkap. Laporan tersebut diserahkan kepada Dinas Pendidikan dan
Kebudayaan Kabupaten Belitung. Khusus untuk MAN Tanjungpndan dan MA Darul Arofah Sijuk laporan ditujukan kepada Departemen Keagamaan Kabupaten Belitung.

Kendala yang Dihadapi oleh Kepala Tenaga Administrasi dalam Melaksanakan Fungsi Manajemen Administrasi

Pelaksanaan kompetensi manajerial kepala tenaga administrasi sekolah tidak terlepas dari kendal-kendala yang menyebabkan kerja kepala tenaga 
administrasi kurang maksimal. Berdasarkan hasil wawancara, seluruh kepala tenaga administrasi sekolah belum memiliki dan belum pernah membaca Peraturan Menteri Pendidikan Nasional (Permendiknas) Nomor 24 Tahun 2008 tentang standar tenaga administrasi sekolah/madrasah. Oleh karena itu, mereka tidak mengetahui kompetensi apa yang harus mereka miliki. Mereka menjalankan tugas sebagai kepala tenaga administrasi hanya mengacu pada aturan sekolah dan dinas sehingga kompetensi yang mereka miliki terbentuk berdasarkan tugas yang mereka kerjakan sesuai aturan tersebut. Jika kepala tenaga administrasi sekolah mengetahui kompetensi apa saja yang harus mereka miliki, maka diharapkan mereka bisa melakukan pengembangan diri sendiri dalam meningkatkan kompetensi yang diamanatkan dalam Peraturan Menteri Pendidikan Nasional (Permendiknas) Nomor 24 Tahun 2008 tentang standar tenaga administrasi sekolah/madrasah.

Menurut kepala tenaga administrasi sekolah, selama ini belum pernah ada kegiatan sosialisasi permendiknas tersebut yang dilakukan oleh Dinas Pendidikan dan Kebudayaan Kabupaten Belitung. Meskipun seharusnya kepala tenaga administrasi bisa mengakses permendiknas tersebut dari internet, sebaiknya dinas juga melakukan kegiatan sosialisasi kepada kepala tenaga administrasi sekolah sehingga mereka bisa lebih memahami kompetensi yang harus mereka miliki sebagai kepala tenaga administrasi sekolah.

Kendala lainnya adalah belum adanya pelatihan tentang kompetensi kepala tenaga administrasi sekolah, khususnya kompetensi manajerial. hal inilah yang menyebabkan beberapa kepala tenaga admnistrasi sekolah kurang maksimal dalam pelaksanan fungsi manajerial, misalnya mengorganisasikan staf, mengambil keputusan, mengoptimalkan pemanfaatan sumber daya, membina staf, dan mengelola konflik. Pelatihan perlu dilakukan supaya kemampuan kepala tenaga admnistrasi sekolah semakin meningkat.

Ada tiga kepala tenaga administrasi sekolah yang merupakan guru di sekolah tersebut. Kondisi ini menyebabkan kerja kepala tenaga administrasi sekolah kurang maksimal karena mereka harus membagi konsentrasi pekerjaan antara tugas guru dan tugas sebagai kepala tenaga admnistrasi. Selain itu, hanya ada dua kepala tenaga administrasi yang memiliki kualifikasi sesuai Permendiknas Nomor 24 tahun 2008, sedangkan yang lainnya lulusan SMA/SMK kecuali kepala tenaga admnisitrasi yang dirangkap oleh guru adalah lulusan S1 Pendidikan.

\section{E. PENUTUP}

Dari pembahasan diatas maka dapat disimpulkan bahwa kompetensi manajerial kepala tenaga admnistrasi sekolah di Kabupaten Belitung secara keseluruhan termasuk kriteria sangat baik dengan rerata skor 3,44. Meski demikian ada beberapa sub kompetensi yang masih perlu ditingkatkan lagi yaitu kompetensi mengorganisasikan staf, mengambil keputusan, mengoptimalkan pemanfaatan sumber daya, membina staf, dan mengelola konflik. Tetapi, ada kendala yang dihadapi oleh Kepala tenaga admnistrasi sekolah dalam melaksanakan kompetensi manajerial adalah kepala tenaga administrasi belum mengetahui kompetensi apa saja yang harus mereka miliki sesuai Permendiknas Nomor 24 Tahun 2008 tentang standar tenaga administrasi sekolah/madrasah, belum ada pelatihan khusus tentang kompetensi manajerial, dan rangkap jabatan yang membuat sebagian kepala tenaga administrasi kurang maksimal dalam menjalan kompetensi manajerial. 


\section{DAFTAR PUSTAKA}

Azwar, Saifuddin. (2010). Penyusunan Skala Psikologi. Yogyakarta: Pustaka Pelajar.

Depdikdas. Undang-Undang RI Nomor 20, Tahun 2003, tentang Sistem Pendidikan Nasional.

Depdiknas. Peraturan Pemerintah RI Nomor 19, Tahun 2005, tentang Standar Nasional Pendidikan.

Djaali \& Pudji Muljono. (2008). Pengukuran dalam bidang pendidikan. Jakarta: PT Gramedia.

Gie, The Liang. (2009). Administrasi Perkantoran Modern. Edisi keempat. Yogyakarta: Liberty Yogyakarta

Kementerian Pendidikan Nasional. Peraturan Menteri Pendidikan Nasional (Permendiknas) Nomor 24 Tahun 2008 tentang Standar Tenaga Administrasi Sekolah/Madrasah.

Moekijat. (2008). Administrasi Perkantoran. Bandung: Mandar Maju
Muhyadi. (2013). Kualifikasi dan Kompetensi Tenaga Administrasi Sekolah Di Daerah Istimewa Yogyakarta.JURNAL

KEPENDIDIKAN, Volume 43, Nomor 1, Mei 2013, Halaman 39 50 ,

http://download.portalgaruda.org/ar ticle. 25 April 2015

Surya, Priadi. (2012). Peran Penting Tenaga Administrasi Sekolah dalamPenguatan Budaya Sekolah untuk ImplementasiPendidikan Karakter. http://staff.uny.ac.id/, 25 April 2015

Zahro, Nafsiatuz dan Imam Baehaki.(2013), Pengaruh Kompetensi Tenaga Administrasi Sekolah terhadap Kinerja Pegawai Tata Usaha pada MTsN dan MAN di Kabupaten Kediri. Jurnal Ilmu Manajemen, REVITALISASI, Vol. 2.Nomor 2, $\quad$ (Juni). http://pascauniskakediri.ac.id/filesJurnalMhs/ Nafisatus \%20Z, 25 April 2015. 